Gábor Pusztai

\title{
Altijd had ik de behoefte de wereld te zien
}

Interview met Melinda Kónya

U werkt in Den Haag, in de Koninklijke Bibliotheek. Wat is uw functie precies?

Ik ben collectiespecialist klassieke en moderne talen en coördinator schenkingen van de KB, de Nationale Bibliotheek van Nederland.

Hoe bent u collectiespecialist geworden?

Waar zal ik beginnen? Ik kom uit Transsylvanië, uit Marosvásárhely. Mijn vader studeerde biologie en was conservator in een natuurhistorisch museum in mijn geboortestad. Mijn moeder was secretaresse van een toneelschool. Na mijn eindexamen in 1977 heb ik Roemenië verlaten. Ik deed nog een toelatingsexamen omdat ik in Kolozsvár Engels en Duits wilde studeren. Later hoorde ik dat ik niet was aangenomen. Maar toen het resultaat bekend werd gemaakt was ik al in Nederland.

\section{Hoe komt dat?}

Mijn hele leven wilde ik eigenlijk altijd Japans studeren. Dat was een droom van mij. Maar in Roemenië Japans studeren in de jaren '70 was voor mij onmogelijk. Het was de diepste Ceausescu-tijd. De interesse voor Japans zat in de familie. Ik had ook een neef, Dezső Benedek (1950), 
die later professor is geworden in oosterse talen aan de University of Georgia in de Verenigde Staten. Ik bewonderde hem heel erg. Hij sprak zeer veel talen en gaf mij boeken. Ik had ook een briefpartner in Japan, een vriendin, maar het was hopeloos. Je kon in Boekarest wel Japans studeren, maar dan kwam je automatisch terecht in de diplomatieke dienst. En dat was niet weggelegd voor een meisje uit een minderhedengroep. Hongaren werden tot deze studie bij voorbaat niet toegelaten. Daarom heb ik voor Duits en Engels gekozen. Ik kreeg van mijn ouders na mijn eindexamen als beloning voor mijn goede resultaten een reis cadeau. Ik mocht naar Hongarije, Tsjechoslowakije en Oost-Duitsland. Het was heel wat in die tijd, zo een treinreis van enkele weken. Van Boedapest reisde ik door naar Dresden en Leipzig. Maar ik moet nog vertellen dat ik toen al jaren bevriend was met een Nederlands lerarenechtpaar. Ik heb ze op een camping in de Karpaten ontmoet, toen ik nog op de middelbare school zat. Ze waren ongeveer tien jaar ouder dan ik en erg aardig. We schreven elkaar brieven, maar ze stelden soms domme vragen, zoals: 'Heb jij eigenlijk een goed leven in Roemenië? Heb je geen zin het Westen te zien?' De brieven werden natuurlijk gecontroleerd, de politie las mee en het resultaat was dat ze op een gegeven moment niet meer Roemenië in mochten. Ik werd door de politie in de gaten gehouden, mijn brieven werden geopend. Ik heb mijn brieven toen op aanraden van mijn vader altijd met een doorslag geschreven. Ik moest ervoor zorgen dat ik een kopie had voor de zekerheid. Ik heb helemaal geen gevaarlijke dingen in mijn brieven gezet, het echtpaar uit Nederland was te direct met zijn vraagstelling en dat zorgde voor problemen. De Securitate, de beruchte Roemeense geheime dienst, las altijd mee. Ooit werd ik - toen zat ik in de zesde klas van het lyceum - uit het klaslokaal gehaald door de Securitate en een officier heeft me uitgevraagd over mijn Nederlandse briefpartners. Hij vroeg of dat allemaal nodig was zo een correspondentie met de Nederlanders. Ik heb geantwoord dat ik alle brieven in kopie had, dus als hij deze wilde lezen, dan was dat ook mogelijk. Maar dat wilde hij niet en hij heeft het erbij gelaten. Zo, dus ik was op reis en vanuit Boedapest heb ik aan dit Nederlands echtpaar een bericht gestuurd dat ik drie weken lang op reis was en dat ik ook naar Oost-Duitsland ging. En dat als ze zin hadden mij te zien, ze dat mij moesten laten weten, en we dan elkaar in Dresden of Leipzig zouden kunnen ontmoeten. En zijn ze op een zaterdag naar Leipzig gekomen. We hebben een praatje gemaakt, ze vroegen wat ik van plan was. Ze wisten dat ik weg wilde uit Roemenië, maar de vraag was hoe? 


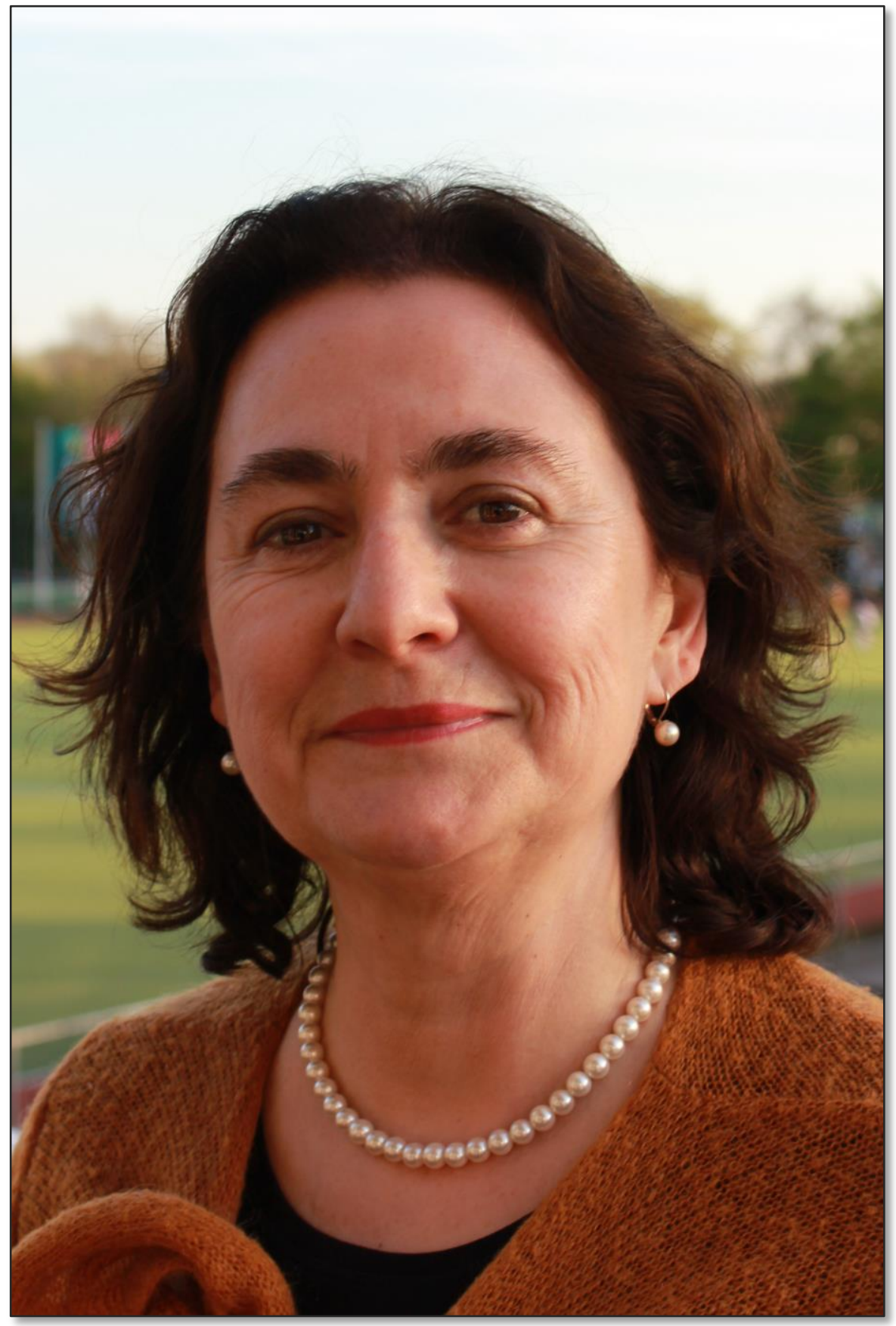

Melinda Kónya 
Ik vertelde dat ik een toelatingsexamen had gedaan voor de universiteit, dat ik niet wist of ik was toegelaten, maar dat als het niet zou lukken ik een jaar zou werken en het een jaar later weer zou proberen. Ze zeiden op een gegeven moment dat ze nu terug naar Nederland gingen en vroegen wat ik van plan was. Ik antwoordde dat ik naar Eisenach, naar de geboortestad van Bach, wilde gaan, de stad zien en dan doorgaan met mijn reis. Toen zeiden ze dat ik met hen mee kon rijden omdat vlak bij Eisenach de grensovergang was naar West-Duitsland. En in Eisenach zeiden ze tegen mij, laat ons verder rijden naar de grens, misschien kunnen we jou meenemen. Als het niet lukt, dan brengen we jou terug naar de stad. Het was natuurlijk enorm naïef van hen. Het was hartstikke gevaarlijk. Maar we stonden in de rij voor de grensovergang. Ik zat voorin in de auto, naast de chauffeur. Aan de Oost-Duitse grenssoldaat liet ik mijn Roemeens paspoort zien. In mijn paspoort was zo'n velletje papier van de Roemeense autoriteiten, een soort passeerbewijs voor de landen waar ik naar toe mocht. Dat was de 'talon de iesire'. Het waren allemaal afkortingen van de landen in het Roemeens. De grenswacht keek naar mijn papieren, dan keek hij naar mij en zei toen: 'Gute Reise!' Een paar honderd meter verder waren we bij de West-Duitse grenspost en daar hebben we natuurlijk meteen gezegd hoe we over de grens zijn gekomen. De reactie van de West-Duitser was: 'Tja, Deutsche Gründlichkeit!' Je kunt natuurlijk jarenlang nadenken, hoe dat allemaal mogelijk was, maar ik denk dat er twee mogelijkheden zijn. De Oost-Duitse grenspost moet gedacht hebben dat niemand zich zo'n enorme brutaliteit kan veroorloven, zonder geldige papieren aan de grens, gewoon in de auto voorrijden en over de grens willen. Daarom dacht hij niet eraan dat ik met mijn paspoort eigenlijk niet over de grens mocht. Of hij moest gedacht hebben: een meisje van achttien, niemand zou haar zoeken, laat haar maar passeren. Misschien.

De Oost-Duitse grenssoldaten waren toen niet per se bekend vanwege hun humaniteit en menselijke medegevoel.

Nee. Het moet dus een vergissing geweest zijn. Maar ik was opeens in het Westen. Het was midden in de nacht. En de vrienden vroegen mij, wat nu? Ik kende op dat moment geen vrienden die naar West-Duitsland waren ontsnapt, ik kende er niemand. En mijn Nederlandse vrienden zeiden toen: rij toch met ons mee naar Nederland. En dat heb ik dan gedaan. Bij de Nederlandse grens heb ik meteen asiel aangevraagd en kreeg 
meteen een voorlopige verblijfsvergunning. In de jaren ' 70 ging het wel wat makkelijker dan nu. De eerste week heb ik bij dat echtpaar doorgebracht. Van daar ben ik bij een andere familie met kleine kinderen terechtgekomen. Ik moest wel naar de politie waar een heel aardige, lieve agent mij vragen heeft gesteld. Het ging heel humaan in die tijd, in de zomer van 1977. Ik wist meteen dat ik wilde studeren, en wel Japans. Ik ging naar Leiden, maar omdat het al augustus was kon ik niet meteen in september met mijn studie beginnen. Ik moest eerst een examen geschiedenis doen en in de lente van 1978 kon ik in Leiden beginnen. Ik kreeg een studentenkamer, ik werd aangenomen, ik was ingeschreven als student en ik kreeg een beurs van de UAF (Stichting voor VluchtelingStudenten). Het was eigenlijk $60 \%$ beurs en $40 \%$ lening die ik na mijn studie moest terugbetalen. Het was voldoende om ervan te leven. Ik studeerde zes jaar Japanse taal- en letterkunde. Tijdens mijn studie had ik al baantjes bij Japanse bedrijven, zoals Mitsubishi en Japanse verzekeringsmaatschappijen. Ik heb na vijf jaar mijn Nederlandse staatsburgerschap gekregen en het duurde nog een jaar tot ik van mijn Roemeense af was. Ik moest 800,- DM aan de Roemeense ambassade betalen om uitgeschreven te worden. Dat was toen een enorm bedrag. Het duurde zes jaar voordat ik weer naar mijn ouders terug op bezoek kon. Maar zij mochten eigenlijk vrij snel naar Nederland. Mijn moeder mocht alleen, zonder mijn vader in 1980 naar Nederland en drie jaar later mocht mijn vader mij komen bezoeken, ook alleen, zonder mijn moeder dus. Mijn twee broers mochten echter voor de val van de muur niet naar Nederland.

\section{Hoe hebben uw ouders het vernomen dat u niet meer terug zou komen?}

Nog voor mijn vertrek heb ik met mijn vader erover gesproken dat ik eventueel niet terug zou keren naar mijn geboorteland en ik had zijn goedkeuring. Hij zei alleen: 'Doe geen domme dingen!' Hij bedoelde hiermee dat ik niet door maisvelden moest gaan rennen of mij in treinen verstoppen. Hij wist dus wat ik van plan was. En we wisten ook dat, als mijn vluchtpoging zou slagen, hij onder druk zou worden gezet door de Securitate. Ik heb met mijn vader de afspraak gemaakt dat ik niet terug zou komen naar Roemenië, wat ik van hem ook zou horen, wat hij mij ook zou schrijven of zeggen. Alleen als hij mij zou schrijven 'nu moet je echt naar huis komen' dan zou het voor mij inderdaad tijd zijn om weer naar mijn ouders te gaan. Dat was de afspraak, deze zin was onze code. Als ik dit vertel krijg ik altijd tranen in mijn ogen. Maar toen mijn ouders 
hoorden wat er gebeurd was, dat ik in het Westen was, waren ze natuurlijk erg geschrokken. Mijn vader werd toen inderdaad onder druk gezet door de Securitate om mij terug te lokken. Ze hebben het geprobeerd. De agenten hebben drie maanden lang mijn vader lastiggevallen en hem onder druk gezet. Hij werd ervan beschuldigd aan mijn ontsnapping meegewerkt te hebben, omdat een meisje van achttien dit nooit voor elkaar zou kunnen krijgen. Op last van de agenten schreef hij brieven aan mij waarin hij mij vroeg terug te komen, maar die bewuste zin die wij hebben afgesproken, stond nooit in de brieven. Ik wist dus dat ik moest blijven. Hij werd dan ook op een bepaalde manier gestraft door de Securitate. Hij was een jager, maar moest zijn jachtgeweren inleveren en hij heeft op zijn werk geen promotie meer kunnen maken. Mijn vader heeft wel voor elkaar gekregen dat al mijn diploma's en documenten uit Roemenië werden gesmokkeld dat ik die uiteindelijk hier heb gekregen. Mijn geboorteakte, mijn eindexamengetuigschrift enzovoort.

\section{U hebt dus Japans kunnen studeren in Leiden.}

$\mathrm{Ja}$, in 1984 was ik afgestudeerd en met mijn Nederlands paspoort kon ik eindelijk naar Japan. Ik was een jaar in Okaiama. Ik heb oude Nederlandse anatomieboeken, uit de achttiende eeuw, vertaald. Terug in Nederland heb ik met een aantal collega's bij een onderneming gewerkt in Amsterdam Japan Europe Promotion. We werkten erg veel voor de Japanse televisie. Dat waren leuke jaren. Ik heb veel gereisd, veel filmopnames gemaakt en ik heb toen de rest van Europa kunnen zien. Ik ging trouwen en in 1993 werd mijn zoon Thomas geboren. Toen moest ik stoppen met werken. Ik kon niet meer reizen. Ik moest iets anders vinden en ik ben als vrijwilligster in de bibliotheek van Japanologie aan de Universiteit Leiden terechtgekomen. Ik heb daar tweeënhalf jaar gewerkt, maar het was op vrijwillige basis. Ik kreeg geen aanstelling en ook geen salaris. En op een gegeven moment zocht de KB titelbeschrijvers. Ik heb gesolliciteerd en ik werd meteen aangenomen. Dat was in 1999. In het eerste jaar werkte ik dus bij de afdeling catalogisering en later ben ik naar de afdeling acquisitie gegaan. Ik werk hier in de $\mathrm{KB}$ al eenentwintig jaar. Ik kon mij altijd ontwikkelen en promotie maken, dat was aantrekkelijk aan die baan. En ik kon bereiken wat ik wilde bereiken. Ik ben nu 62, maar het werk vind ik nog steeds erg spannend. Het is heel divers wat ik doe, een prachtige wereld. Ik ben hier erg gelukkig. 
Komt $u$ in aanraking met Hongaarse cultuur?

Ik heb in Nederland vrij snel kennisgemaakt met Hongaarse families. Zij hebben mij meegenomen naar de Mikes Kelemen Kör, een Hongaarse vereniging voor cultuur en literatuur in Vianen. We hadden ook jaarlijkse conferenties ergens in het land. Dat waren zeer interessante bijeenkomsten. Ik heb toen veel grote schrijvers ontmoet, zoals Péter Eszterházy en Péter Nádas, maar er waren er ook Hongaarse kunstenaars, artiesten en acteurs uit het buitenland. Op deze manier ben ik altijd met Hongaarse taal en cultuur in contact gebleven.

\section{Hoe is het Hongaarse culturele leven in Nederland op dit moment?}

Het is in de afgelopen 42 jaar heel erg veranderd. Toen ik de eerste keer naar zo'n Mikes bijeenkomst ging, waren daar vooral mensen die als jongelui in 1956 naar Nederland waren uitgeweken. Dus in de jaren ' 70 waren ze van middelbare leeftijd. Ze hadden behoefte aan Hongaarse cultuur op niveau. Dus niet alleen maar volksdansen en borduren, maar lezingen en conferenties. Maar hun kinderen, de tweede generatie, dat en is een totaal ander verhaal. Weinigen van deze kinderen spreken nog goed Hongaars en de Hongaarse cultuur en literatuur kennen ze niet. Het zegt ze niet zo veel, ze zijn niet echt erin geïnteresseerd. Ze zijn goed geïntegreerd in de Nederlandse maatschappij en voelen zich meer Nederlander dan Hongaar. De Hongaren die nu in Nederland verblijven zijn vooral mensen die hier komen werken voor een kortere of langere periode. Ze hebben totaal andere behoeftes en hun situatie is ook compleet anders. Ze kunnen ieder moment terugkeren naar hun eigen land, wat de emigranten in de jaren ' 70 en ' 80 niet konden. Deze emigranten waren gedwongen hier ter plekke te zoeken wat ze aan eigen cultuur misten. Maar nu dat de grenzen open zijn gegaan, is zoiets niet meer nodig. En toen had je geen internet en Facebook. De contacten waren anders. $\mathrm{Nu}$ wonen er zeer veel Hongaren in Nederland, maar de contacten en bijeenkomsten vinden plaats in kleine kring. Het kerkelijk leven is ook goed georganiseerd. Er zijn in meerdere steden van Nederland tweetalige kerkdiensten en zaterdagscholen voor de kinderen, waar ze goed Hongaars kunnen leren. Er is een Hongaars koor in Amsterdam en ook in Den Haag met veel optredens. De ambassade organiseert ook veel evenementen. Het is haast niet bij te houden. Er zijn eigenlijk zo veel Hongaarse evenementen in heel Nederland dat je je hele 
week hiermee zou kunnen vullen. En als het niet genoeg is, dan kun je ieder moment in het vliegtuig stappen en naar Boedapest vliegen.

Vroeger waren twee belangrijke Hongaarse organisaties in Nederland, de Mikes Kelemen Kör en de Hungaria Club. Hoe is het nu?

$\mathrm{Nu}$ zijn er meer, vooral kleinere organisaties en als paraplu heb je de Hongaarse Federatie. Die heeft een overkoepelende functie. In de zomer wordt een zomerdag georganiseerd voor de kinderen, daar heeft de Hongaarse ambassade een grote rol in gespeeld. Scholen krijgen subsidie uit Hongarije en daardoor hebben ze het wezenlijk makkelijker dan wij het hadden in die tijd. Er zijn veel kleine groepjes, Hongaarse verenigingen verspreid door het hele land, maar ze zijn met te veel. De generatie van de vluchtelingen uit ' 56 waren minder in aantal, maar ze waren een hechte groep. Die generatie sterft langzaam uit. Mensen uit die groep, die nog in leven zijn, zijn ruim boven de 80 .

Komt u nog via uw werk in aanraking met Hongaarse cultuur?

Ja, wij verzamelen Nederlandse boeken, vertaald in het Hongaars en natuurlijk Hongaarse literatuur vertaald in het Nederlands. De KB krijgt ook regelmatig heel mooie kunstboeken van de Nationale Bibliotheek in Boedapest. Literatuur in het Hongaars verzamelen we niet, omdat dit de taak was van de universiteiten waar Hongaars werd gegeven, Amsterdam en Groningen dus. $\mathrm{Zij}$ hebben een grote verzameling Hongaarse boeken, maar de studierichting in Groningen bestaat helaas niet meer. Ze hebben nog geprobeerd de studie breder op te zetten, ze namen naast Hongaars ook Fins erbij, maar het mocht niet baten. Ze hadden te weinig studenten en ze zijn, samen met andere kleine vakgroepen, gesneuveld. Hongaars bestaat niet meer als zelfstandige studie in Nederland, maar in Amsterdam heb je nog de Oost-Europa Studies die ook een Hongaarse poot heeft. Althans Hongaarse cultuur, niet meer de taal. Wat wel heel leuk is, is dat er veel Hongaarse boeken in Nederlandse vertaling verschijnen, dankzij uitstekende vertalers, als Mari Alföldy en Henry Kammer onder anderen. Weet je, ik voel me helemaal thuis in Nederland. Het is prettig wonen in dit land, maar ik voel regelmatig de behoefte aan mijn moedertaal en Hongaarse cultuur. 
Hebt $u$ ooit spijt gehad vanwege uw beslissing dat $u$ uw geboorteland hebt verlaten?

Nee. Absoluut niet. Ik denk dat ik heel ontevreden was geweest als ik niet weg gekund had. Ik had altijd de behoefte om meer van de wereld te zien. Ik moest ruimte hebben. Ik weet nog, ik stond als kind op de zesde etage, in het appartement van mijn ouders in Marosvásárhely uit het raam te kijken. Je zag in de verte de Karpaten. Ik keek en werd boos, het gevoel bekroop mij van wanneer kan ik eindelijk iets anders zien dan dit? En nu, als ik nu in mijn geboortestad ben en uit het raam kijk dan denk ik: goh, wat is het toch mooi hier! Ik heb de wereld gezien, maar het liefst ga ik terug naar Transsylvanië. 